\title{
Bracing of large GFRP frames with very slender GFRP panels
}

\begin{tabular}{|r|l|}
\hline Journal: & IABSE/Vancouver 2017 \\
\hline Manuscript ID & YVR-0505-2017.R2 \\
\hline Theme: & Innovations in Structures \\
\hline Date Submitted by the Author: & n/a \\
\hline Complete List of Authors: & $\begin{array}{l}\text { Macchi, Niccolò; Baechtold \& Moor AG, Structural engineering } \\
\text { Zwicky, Daia; University of Applied Sciences Western Switzerland, School } \\
\text { of Engineering and Architecture }\end{array}$ \\
\hline Material and Equipment: & Composites \\
\hline Type of Structure: & Lightweight Structures \\
\hline Other Aspects: & Innovative Structural Systems, Codes and Standards \\
\hline &
\end{tabular}




\title{
Bracing of large GFRP frames with very slender GFRP panels
}

\author{
Niccolò Macchi \\ Bächtold \& Moor AG, Bern, Switzerland \\ Daia Zwicky \\ University of Applied Sciences Western Switzerland, School of Engineering and Architecture \\ Fribourg, Switzerland \\ Contact: niccolo.macchi@baechtoldmoor.ch
}

\begin{abstract}
Glass fibre reinforced polymers (GFRP) were developed in the first half of the $20^{\text {th }}$ century. They have high strength (especially for tensile stresses), low density, high resistance in corrosive environments, and free formability. Despite these advantages, GFRP materials are not widely used in construction yet. The main reasons are low stiffness of GFRP (relative to its strength) and the absence of codified and generally accepted design standards. Structural engineers typically have limited knowledge and experience with these materials. In this study, an approach to design slender GRFP bracing panels with methods similar to those used for plated steel girders is developed and compared to results of full-size shear tests.
\end{abstract}

Keywords: Composites, Lightweight Structures, Plate Buckling, Panel-Braced Frame 


\title{
Bracing of large GFRP frames with very slender GFRP panels
}

\author{
Niccolò Macchi
}

Bächtold \& Moor AG, Bern, Switzerland

Daia Zwicky

University of Applied Sciences Western Switzerland, School of Engineering and Architecture Fribourg, Switzerland

Contact: niccolo.macchi@baechtoldmoor.ch

\begin{abstract}
Glass fibre reinforced polymers (GFRP) were developed in the first half of the $20^{\text {th }}$ century. They have high strength (especially for tensile stresses), low density, high resistance in corrosive environments, and free formability. Despite these advantages, GFRP materials are not widely used in construction yet. The main reasons are low stiffness of GFRP (relative to its strength) and the absence of codified and generally accepted design standards. Structural engineers typically have limited knowledge and experience with these materials. In this study, an approach to design slender GRFP bracing panels with methods similar to those used for plated steel girders is developed and compared to results of full-size shear tests.
\end{abstract}

Keywords: Composites, Lightweight Structures, Plate Buckling, Panel-Braced Frame

\section{Introduction}

Glass fibre reinforced polymers (GFRP) are lightweight, high resistance materials that have the added advantage of being resistant to a multitude of chemically aggressive environments. However, there are problems that still hinder widespread use of FRP in load-bearing structural applications, e.g.:

Commercially available GFRP profiles usually do not exceed $300 \mathrm{~mm}$ in height and thus limit possible span lengths. Higher beam depths are required for longer spans in order to attain sufficient stiffness at serviceability limit state (SLS), being usually governing for the design of GFRP structures [1].

This can be overcome by assembling commercially available GFRP pultruded U-profiles with thin panels to larger structural elements. Designing flat
GFRP panels, being primarily loaded by in-plane shear, is done today by considering elastic buckling analysis only. These thin panels have, however, a considerable post-critical resistance that is not considered in today's GFRP design.

Steel design provides approaches to construct high inertia thin-plated girders. Methods to assess post-critical resistance for economical design are implemented in current building codes.

The shear panel models for steel rely on its capability to redistribute stresses within tension fields. (Mild) steel is admittedly a ductile material, whereas GFRP is usually considered brittle.

Another obstacle for widespread use of GFRP is the relative complexity of composite material models compared to traditional construction materials. Simplified but mechanically sound constitutive laws would certainly improve the application potential of (G)FRPs in construction. 


\section{Development of constitutive law}

\subsection{GFRP Sheets}

The material used for this study [2] is described in the EN 60893 [3] series of standards. It is an epoxy resin (EP) reinforced with woven glass fibre sheets (GC). Additionally, the material is selfextinguishing (202). So, its denomination after EN 60893-3-1 is EPGC 202. These standards mainly target the electronics industry and only specify a minimum mechanical strength.

The panels are built up from multiple layers of biaxial plain weave cloth and have a fibre content of approximately $55 \%$.

The cloth used in the fabrication of the composite is a plain weave glass fibre cloth with slightly varying fibre content (and/or crimp) in the two principal directions. This is visible in the delaminated composite (Figure 1) and at comparing mechanical properties. The orthogonal directions of fibre alignment will be referred to as 1 for the stronger and 2 for the weaker, respectively.

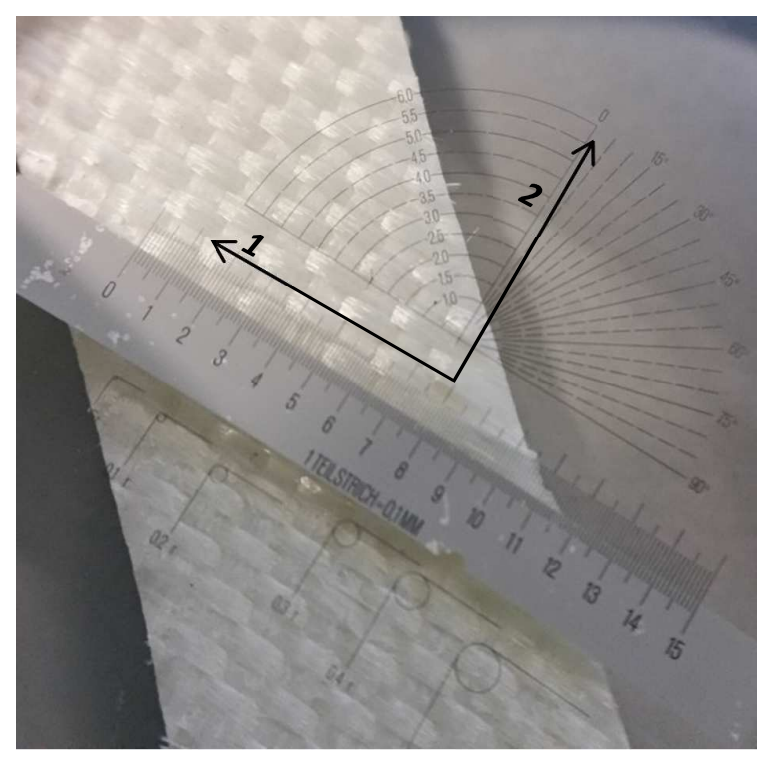

Figure 1. View of delaminated composite and principal axes

\subsubsection{Tension tests at different angles w.r.t. principal fibre directions}

To assess more closely the mechanical properties of the panels, tension tests in different direction with regard to the principal direction 1 (at $0^{\circ}, 15^{\circ}$, $30^{\circ}, 45^{\circ}, 60^{\circ}, 75^{\circ}$ and $90^{\circ}$, respectively, the latter equalling direction 2) have been conducted [2] on dog-bone specimens as specified in ISO 527-4 [4].

Young's modulus, ultimate strength and strain, and a bi-linear material law, based on the same integral of the stress-strain curve, have been derived from the test results.

To interpolate material behaviour under arbitrary angles, an analytical constitutive law for tensile stresses at variable angle has been developed [2].

\subsection{Analytical material model for tensile stresses at arbitrary angles}

To analyse the tensile stresses of an orthotropic composite in an arbitrary direction, the action must be decomposed into the main directions 1 and $\mathbf{2}$ of the composite. The stress transformation can be derived by establishing equilibrium conditions, eq. (1), for the two systems shown in Figure 2.
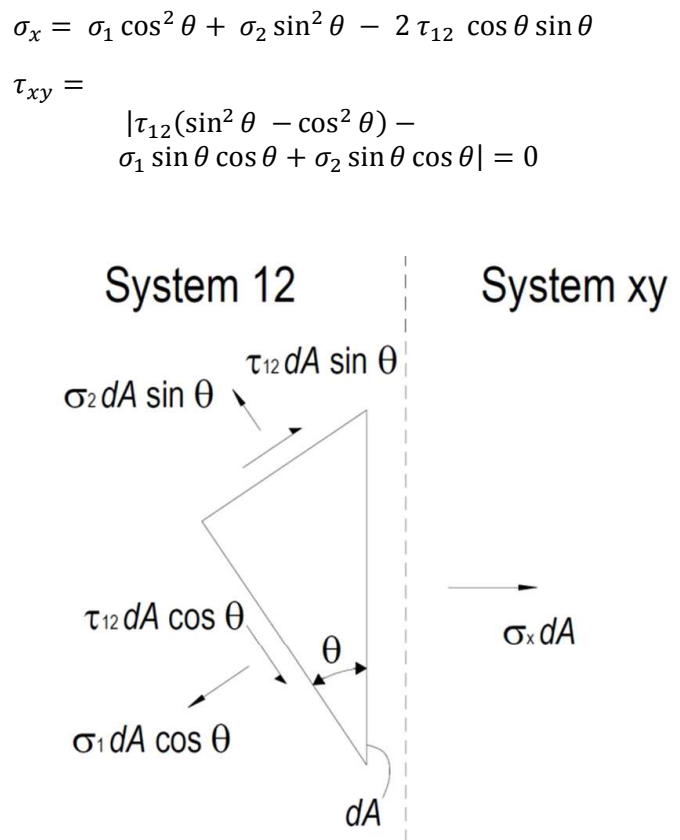

Figure 2. System of equivalent stresses for uniaxial tension 


\subsubsection{Young's modulus}

Composite theory [5] gives a solution for arbitrary direction stiffness, eq. (3). $E_{1}$ and $E_{2}$ can be derived directly from the material tests. Shear modulus $G_{12}$ and Poisson ratio $v_{12}$ must be determined analytically. $G_{12}$ can be derived by solving eq. (3) for the $45^{\circ}$ direction and using the associated elastic modulus. The Poisson ratio for epoxy composites can be assumed to be 0.2 . Figure 4 shows the initial stiffness of the tested composites (yellow line) and the measured data.

\subsubsection{Yield strength and strain}

Yield strength and strain are directly linked by Hooke's law. The yield strain in all directions was nearly identical (7.96\%, COV $5.5 \%)$, corresponding to the cracking strain of the epoxy matrix. A constant yield strain and an associated yield stress, using eq. (3), is thus assumed for all directions, as shown in Figure 4 (blue line and associated data).

\subsubsection{Ultimate tensile strength and strain}

Ultimate unidirectional tensile strength in an arbitrary direction of the panel can be derived by eq. (4), where $f_{u, \exp }$ is the breaking strength of the $0^{\circ}$ direction and $f_{u, \text { exp }}$ of the $90^{\circ}$ direction. $\tau_{\max }$ eq. (5), is determined by solving eq. (1) for the $45^{\circ}$ direction using the measured $45^{\circ}$ panel strength.

The fibres in the composite are loaded up to the breaking strength of the cloth. The shear stress

$$
\begin{gathered}
E_{x}=\frac{1}{\frac{1}{E_{1}} \cos ^{4} \theta+\left[-\frac{2 v_{12}}{E_{1}}+\frac{1}{G_{12}}\right] \cos ^{2} \theta \sin ^{2} \theta+\frac{1}{E_{2}} \sin ^{4} \theta} \\
\tau_{u, \theta}=f_{u, 1} \cos ^{2} \theta+f_{u, 2} \sin ^{2} \theta-\tau^{*} \\
\tau^{*}=\operatorname{minimum}\left\{\begin{array}{c}
2 \cos \theta \sin \theta\left(f_{u, 1} \cos ^{2} \theta+f_{u, 2} \sin ^{2} \theta\right) \\
\frac{f_{u, 1} \cos ^{2} 45^{\circ}+f_{u, 2} \sin ^{2} 45^{\circ}-f_{u, 45^{\circ}}}{2 \cos 45^{\circ} \sin 45^{\circ}}=\tau_{\max }
\end{array}\right. \\
\varepsilon_{u}=\max \left\{\begin{array}{c}
\varepsilon_{u, 1} \cos ^{2} \theta \\
\varepsilon_{u, 2} \sin ^{2} \theta \\
\varepsilon_{u, 12}(\cos \theta \sin \theta)^{2}
\end{array}\right. \\
\varepsilon_{u, 12}=\frac{\varepsilon_{u, 45^{\circ}}}{\left(\sin \left(45^{\circ}\right) \cos \left(45^{\circ}\right)\right)^{2}}
\end{gathered}
$$




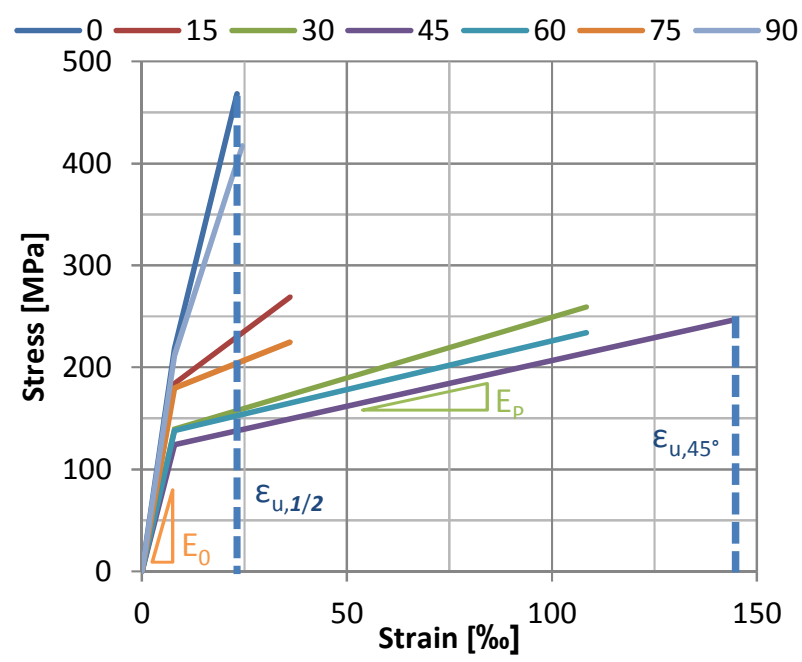

Figure 3. Bi-linear model of tensile behaviour of orthogonal GFRP at different angles [2]

\section{Full size tests of shear panels}

\subsection{Vierendeel beam}

To test the post-critical shear capacity at different aspect ratio of thin GFRP panels, a braced GFRP Vierendeel beam has been loaded eccentrically as seen in Figure 5 [2]. The laterally held girder was assembled by $\varnothing 12$ bolts of steel quality 4.6 .

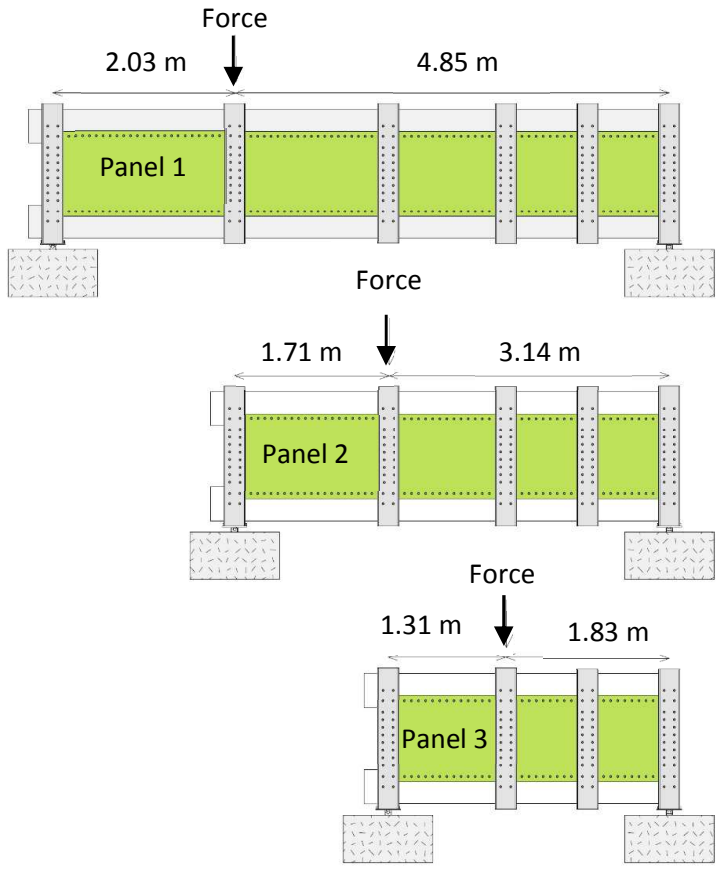

Figure 5. Test setups for shear panels

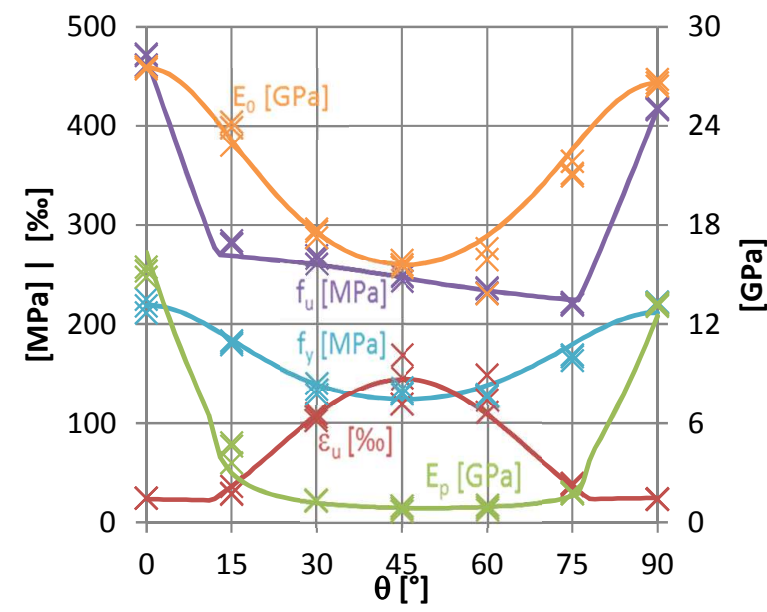

Figure 4. Parameters of the material model, test data overlaid as crosses [2]

\subsection{Shear panels}

The geometry of the shear panels has been chosen to represent realistic aspect ratios and slenderness. To see the influences of the aspect ratio, three different types of panels have been tested (Table 1). The influence of slenderness has been tested in a previous study [1].

Table 1. Geometry of tested shear panels

\begin{tabular}{|c|c|c|c|}
\hline Panel & 1 & 2 & 3 \\
\hline Thickness $\left(\mathrm{t}_{\mathrm{w}}\right)[\mathrm{mm}]$ & \multicolumn{3}{|c|}{4} \\
\hline Height (b) [mm] & \multicolumn{3}{|c|}{800} \\
\hline Width (a) [mm] & 1917 & 1600 & 1200 \\
\hline Aspect ratio (a/b) & 2.4 & 2.0 & 1.5 \\
\hline Slenderness $\left(t_{w} / b\right)$ & \multicolumn{3}{|c|}{0.005} \\
\hline $\begin{array}{l}\text { Horizontal / vertical } \\
\text { bolt spacing [mm] }\end{array}$ & $76.7 / 80$ & $76.2 / 80$ & $80 / 80$ \\
\hline
\end{tabular}

\subsection{Test results}

The ultimate loads measured in the full-size tests do not correspond to the shear panel resistances, as the frame also contributes to shear resistance. The influence of different frame node stiffness for panel 2 is shown in Figure 6 . The shear resistance of the frame is limited to $217 \mathrm{kN}$ by the bolted 
connections. The ultimate resistance of the Vierendeel beams braced with shear panels is shown in Table 2.

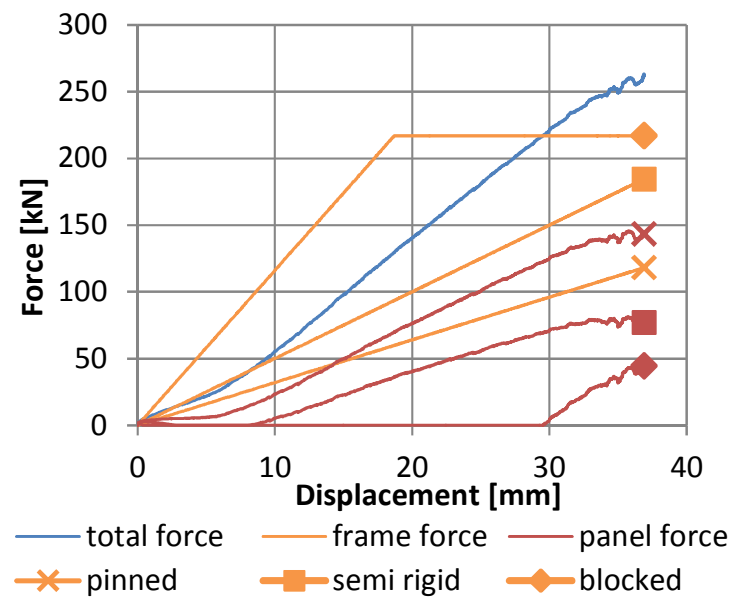

Figure 6. Force distribution in Test 2 between panel and frame for different frame node stiffness

Table 2. Ultimate test loads

\begin{tabular}{l|c|c|c|}
\multicolumn{1}{c|}{ Force \ Panel } & $\mathbf{1}$ & $\mathbf{2}$ & $\mathbf{3}$ \\
\hline Abutment reaction [kN] & 213 & 260 & 322 \\
\hline Panel (blocked nodes) [kN] & 3 & 43 & 105 \\
\hline Panel (semi rigid nodes) [kN] & 91 & 76 & 111 \\
\hline Panel (pinned nodes) [kN] & 170 & 142 & 128 \\
& & &
\end{tabular}

\subsection{Discussion}

As seen in Figure 6, frame stiffness has a huge impact on measured panel resistance, as the resistance of the panel cannot be measured directly in the chosen test setup. The two extremes, pinned and blocked nodes, are indeed not realistic: the theoretical stiffness of the blocked nodes frame is considerably higher than the measured stiffness, meaning that the shear panel hardly gets loaded; with pinned nodes, the resistances of the different aspect ratio panels increase with increasing aspect ratio. A "realistic" frame stiffness was analytically calculated, using the dimensions and geometry of the bolted node connection. This assumption (semi-rigid) gives slightly increasing resistances for the panels with decreasing aspect ratios. The "higher" resistance,
Table 2, of panel 1 might be due to preloading the panel before the final test, as the initial test setup had to be modified due to higher loads than expected.

\section{Dimensioning of GFRP shear panels}

\subsection{Critical buckling force}

The elastic buckling force due to shear loading of thin panels is quite well understood [8]. The critical buckling force, eq. (8), is usually much less than the ultimate resistance, as there is a high post-critical contribution, usually credited to some form of tension field.

$V_{c r}=\tau_{c r} b t_{w}=k \frac{\pi^{2} E}{12\left(1-v^{2}\right)}\left(\frac{t_{w}}{b}\right)^{2} b t_{w}$

The coefficient $k$ (elastic buckling coefficient for pinned panel edges) is $k=5.34+4 / \alpha^{2}$, where $\alpha$ is the panel aspect ratio $a / b$. Shear buckling forces for aspect ratios from 0 to 3 for panel height and thickness as tested are shown in Figure 7. The critical buckling load is between 5 and $10 \mathrm{kN}$ for every reasonable aspect ratio $\alpha>1$. The Poisson ratio is 0.2 for all aspect ratios and $E$ is defined as $E_{x}$, eq. (3), of the diagonal angle $\operatorname{tg} \theta=b / a$.

The critical buckling force slightly reincreases for aspect ratios greater than ca. 1.8. This is due to the elastic modulus increasing with increasing aspect ratios.

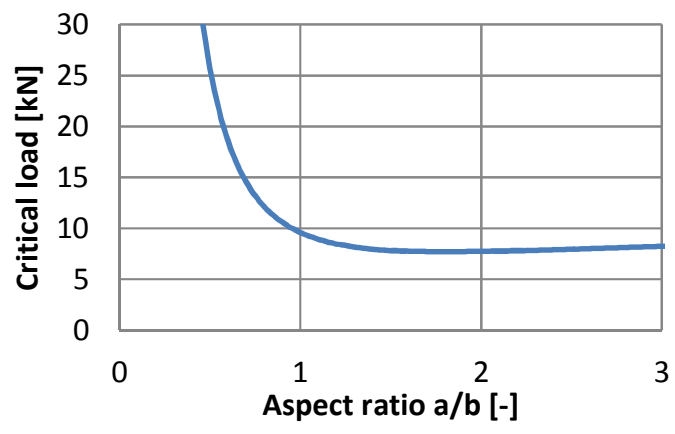

Figure 7. Elastic buckling force of shear panels 


\subsection{Tension fields}

\subsubsection{Basler's model}

For steel plated girders, several methods to assess post-critical resistances have been developed [8]-[10]. Swiss construction codes [11] are based on the tension field approach developed by Basler, Figure 8.

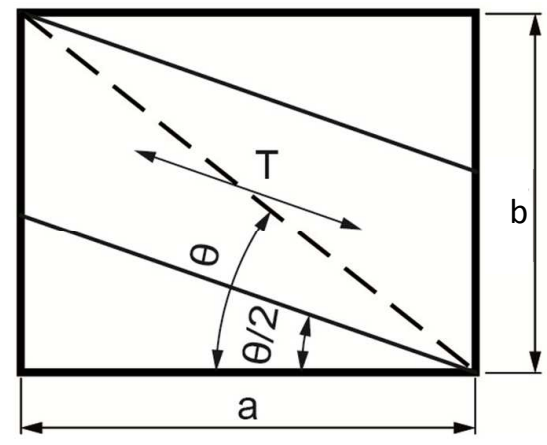

Figure 8. Geometry of Basler tension field [8]

One assumption in the Basler model is that the girder flanges have no bending stiffness. This is not quite true for the specimens tested here. However, a tension field as described by Basler is visible during the test in DIC measurements (Figure 9). In a previous study, the tension field approach has already been shown effective for calculating ultimate shear resistance of thin GFRP shear panels [1]. The tension fields of Basler are developed with the theory of plasticity and are a lower-bound solution for the resistance, as is preferable when designing structures.

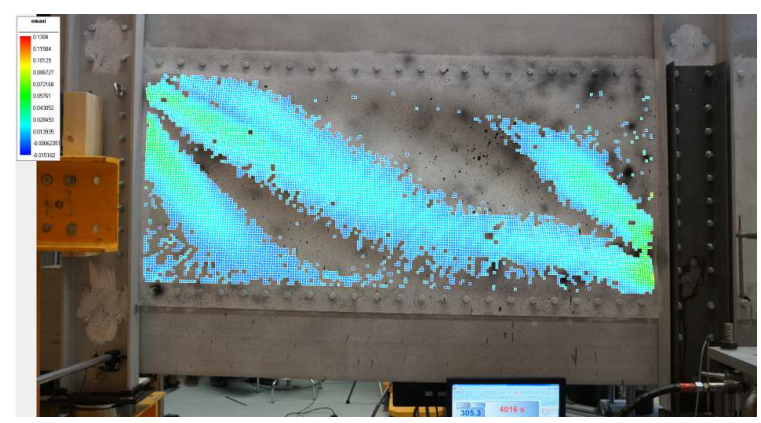

Figure 9. Zones with positive strains in panel during test (DIC visualisation)

The shear resistance is defined as the elastic buckling load plus the contribution of the tension field according to eq. (9):

$$
V_{\sigma}=\frac{0.5 h_{f} t_{w} \sigma_{t}}{\sqrt{1+\alpha^{2}}}=\frac{0.5 h_{f} t_{w}}{\sqrt{1+\alpha^{2}}} * \frac{1-\tau_{c r}}{\tau_{y}} * f_{u}
$$

$f_{u}$ is the material strength with regard to the tension field angle $\theta / 2$ and $\sigma_{t}$ of eq. (10):

$$
\sigma_{t}=\sqrt{f_{y}^{2}-\tau_{c r}^{2}[3-(1.5 \sin \theta)]}-\tau_{c r} \sin \theta
$$

The theoretical resistance of panels with aspect ratios from 0 to 3 , web thickness $4 \mathrm{~mm}$ and $800 \mathrm{~mm}$ height is shown in Figure 10.

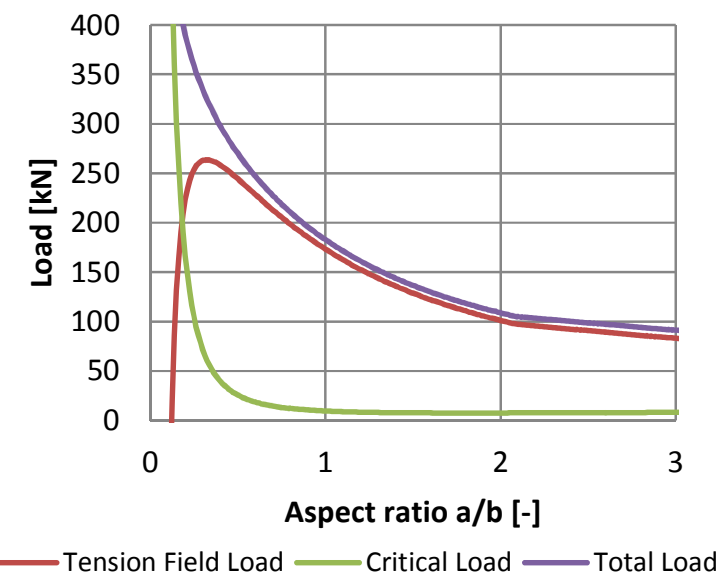

Figure 10. Resistance of shear panels (Basler)

The tension field must be anchored in the girder posts, and contrary to welded steel plate girders where the connection is monolithic, the bolted connection must be able to withstand the tensile stress of the tension field. Mabboux and Zwicky [12] have tested very similar plates in tensile shear with M12 steel bolts. Failure in these tests was plate splitting. As a similar failure occurred during the shear panel tests, an ultimate resistance of $F_{u}=45 \mathrm{kN}$ can be assumed for a $4 \mathrm{~mm}$ panel. The tension field stress thus depends on the maximum connection capacity. Figure 11 shows the comparison of theoretical resistances of shear panels (blue line) with test data. 


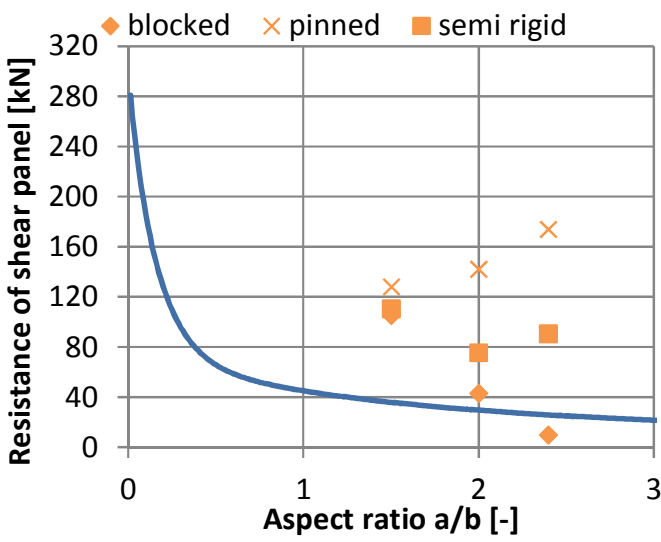

Figure 11. Comparison of test results with Basler's tension field model, corrected for connection resistance

\subsubsection{Tension field overlay model}

The resistances from the full-size tests are considerably higher than the analytical resistances obtained with the Basler model when considering the connection resistance. To better use the capacity of the connectors, a combined model that overlays two tension fields (Figure 12) has been developed.

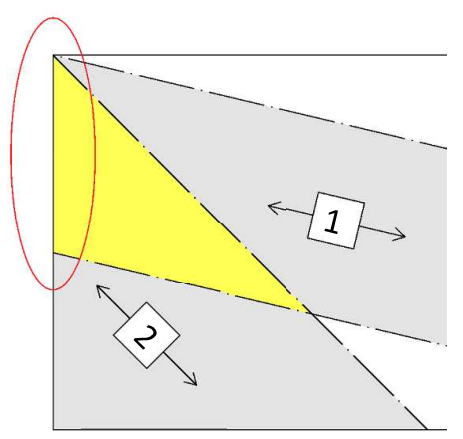

Figure 12. Overlay of tension fields and critical zone for connectors

Tension field 1 has the same geometry as the Basler model. Tension field 2 with a $45^{\circ}$ angle is overlaid. This configuration was chosen due to the zones of positive strains measured during the fullsize tests (Figure 9). The capacity of the connection is divided among the two tension fields by the ratio of the displacements of the geometric middle line (Figure 13).

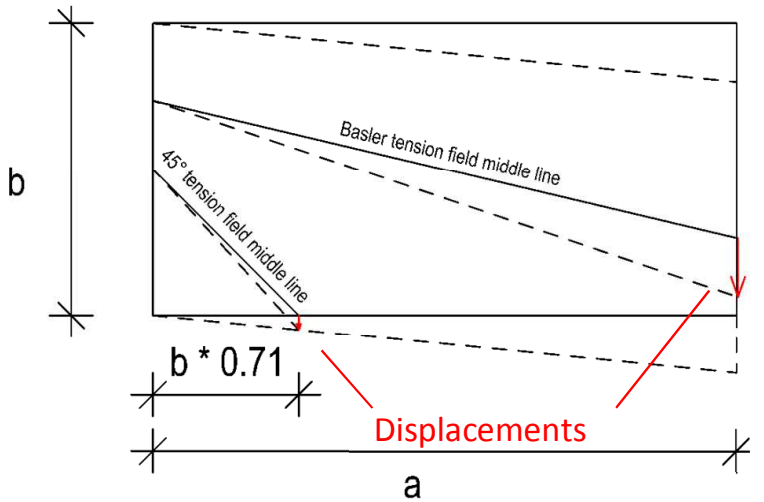

Figure 13. Diagram of transposition for panel deformation

The connection capacity used by tension field 1 (Basler geometry), ratio $k$, is defined in equation (11). The shear resistance of the Panel is defined in equation (12).

$$
\begin{gathered}
k=\frac{\cos \frac{\theta}{2}}{\cos \frac{\theta}{2}+\frac{1}{\alpha * 2}} ; \alpha=\frac{a}{b} \\
V_{u}=k \times V_{\text {Basler }}+(1-k) \times V_{45^{\circ}}
\end{gathered}
$$

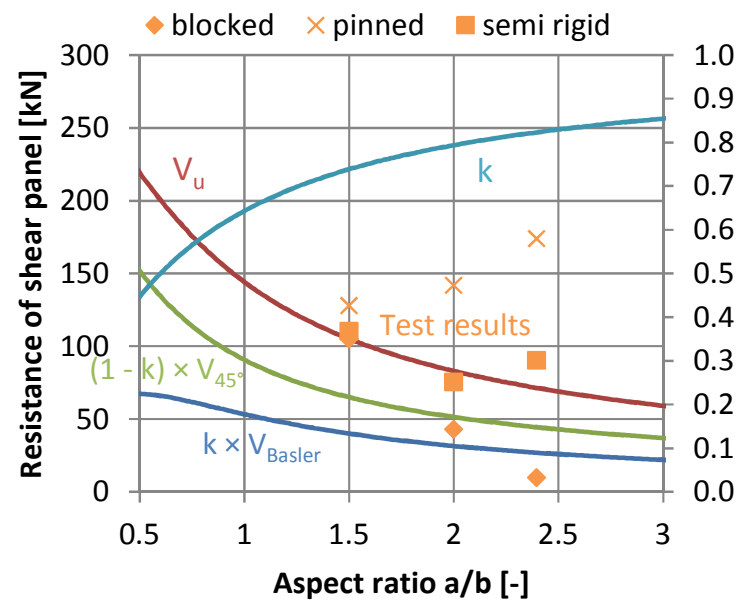

Figure 14. Resistance of shear panels

Figure 14 shows the close agreement of the test data and the analytical model, when considering semi-rigid frame nodes. Blocked and pinned node data points are also visible as lower and upper limits, to show sensibility of the test to frame stiffness. 


\section{Conclusions}

Massive use of GFRP in construction is currently hindered by the lack of knowledge of structural engineers (in the construction industry) and by design methods that are not easily adapted into the design workflow.

GFRP, and FRP in general, are widely used and accepted in engineering practice in other fields. Wind turbine industry heavily relies on GFRP materials for the construction of rotor blades of $100 \mathrm{~m}$ and more. The structural design of the blades is usually done by elastic FEM [13], not considering post-critical resistance. Ultimate load considerations are, however, of interest in building design, as usually serviceability and ultimate load states differ considerably in codes and standards.

The material law developed to determine the tensile strength of orthogonally reinforced GFRP at arbitrary angles is bilinear, and easily adapted into current dimensioning practice in the building industry. It depends on simple material properties that can be derived from a limited number of tests. These tests are a necessity for construction use of market products, as the current standards do not effectively define the mechanical properties of the materials.

The tension field model by Basler, developed for steel plated girders, is easily understood. When connection capacity is included in this model, the Basler tension field predicts very conservative panel resistances. When a second tension field is overlaid for better use of the connection capacity, the analytical values are very close to the test results (assuming semi-rigid frame nodes).

Overall, the dimensioning approach described in this paper is very close to existing codified approaches to similar problems [11], and thus can be easily integrated into building industry workflow.

Future work on this subject should try to simplify test conditions to reduce the influence of frame stiffness on test results. Increasing the range of tested aspect ratios and connector resistances is another way to increase the viability range of these models.

\section{References}

[1] Zwicky D., Mabboux J. Post-Buckling Shear Resistance of Composite Panels. Composites in Civil Engineering CICE. 2014.

[2] Macchi, N. Structural behavior and design of shear panels made of glass fiber reinforced polymers (GFRP shear panels). MSc thesis, School of Engineering and Architecture Fribourg, Univ. of Applied Sciences Western Switzerland, 2016.

[3] BS EN 60893-3-1:2012. Insulating materials. Industrial rigid laminated sheets based on thermosetting resins for electrical purposes. Specifications for individual materials. Types of industrial rigid laminated sheets.

[4] ISO 527-4:1997. Plastics - Determination of tensile properties - Part 4: Test conditions for isotropic and orthotropic fibre-reinforced plastic composites.

[5] Gibson, R. F. Principles of composite material mechanics. CRC press, 2016.

[6] Mallik, P. K. Fiber-reinforced composites: materials, manufacturing, and design. CRC press, 2007.

[7] Hart-Smith, L. J. What the textbooks won't teach you about interactive composite failure criteria. Composite structures: theory and practice. ASTM International, 2001.

[8] Basler, K. Strength of plated girders in shear. Proc. ASCE, 87,(ST7), Oct. 1961, Reprint No. 186 (61-13). 1961.

[9] Höglund, T. Shear buckling resistance of steel and aluminium plate girders. Thinwalled structures, 1997, 29(1):13-30.

[10] Porter, D. M., Rockey, K. C., Evans, H. R. The collapse behaviour of plate girders loaded in shear. University College, Department of Civil and Structural Engineering, 1987.

[11] SIA 263:2013. Stahlbau. Swiss Society of Engineers and Architects, Zurich.

[12] Zwicky, D., Mabboux, J. Shear design of composite panels - post-buckling tension field action. Footbridge 2014.

[13] Griffith, D. T., Ashwill, T. D. The Sandia 100meter all-glass baseline wind turbine blade: SNL100-00, Sandia National Laboratories, Albuquerque, Report No. SAND2011-3779, 2011 